\title{
Del silencio a la agencia. El emerger del cuerpo en las ciencias sociales
}

\author{
From silence to agency. The emergence of the body in \\ Social Sciences
}

Do silêncio à agência. O emergir do corpo nas Ciências Sociais

Morena Goñi*

\section{RESUMEN}

El presente trabajo propone un recorrido por las principales

Palabras clave: representaciones del cuerpo a lo largo de la historia. Desde la cuerpo, dualismo Antigüedad clásica hasta la Modernidad tardía, el cuerpo fue sistemáticamente silenciado como categoría de conocimiento corporal, giro corporal. y subordinado ante la presunta superioridad del alma, la mente o lo no corpóreo. Atendiendo a esto, se esbozan algunos de los postulados más relevantes de disciplinas como la filosofía, la medicina, el arte o la sociología, para arribar, en última instancia, a las consideraciones del posestructuralismo y al denominado "giro corporal". Trazando una ruptura con el dualismo antropocéntrico, este terreno ha sido el encargado de restituir al cuerpo un lugar de privilegio, emancipándolo de su largo letargo y posicionándolo como categoría autónoma de conocimiento.

\begin{abstract}
This paper proposes a journey through central representations of the body throughout history. From classical antiquity to late modernity, the body was systematically silenced as a category of knowledge and subordinated to the presumed superiority of the soul, the mind, or the non-corporeal. In response, we outline some of the most relevant disciplines such as philosophy, me-
\end{abstract} Keywords: body, body dualism, body turn.

\footnotetext{
* Licenciada en Historia por la Universidad Nacional de Rosario (UNR), doctoranda en Ciencias Sociales por la Universidad Nacional de Entre Ríos (UNER). Becaria doctoral CONICET, Auxiliar de Primera Categoría de la cátedra "Espacio y Sociedad" de las carreras de Antropología e Historia de la UNR. Lugar de trabajo: Centro de investigaciones Sociales y Políticas (CISPO) de la Facultad de Ciencias de la Educación (UNER). Paraná, Argentina.morenagoni@gmail.com
} 
dicine, art, or sociology to reflect on post-structuralism and the so-called "body turn." By tracing a break with anthropocentric dualism, this field has been responsible for restoring the body to a place of privilege, emancipating it from its long lethargy and positioning it as an autonomous category of knowledge.

\section{RESUMO}

O presente trabalho propõe um percurso através das principais representações do corpo ao longo da história. Desde a Antiguidade Clássica até a modernidade tardia, o corpo foi sistematicamente silenciado como categoria de conhecimento e subor-

Palavras-chave: corpo, dualismo corporal, giro corporal. dinado frente à presumida superioridade da alma, da mente ou do não corpóreo. Atendendo a isto, são esboçados alguns dos postulados mais relevantes de disciplinas como a Filosofia, a Medicina, a Arte e a Sociologia, para chegar, em última instância, às considerações do pós-estruturalismo e ao chamado "giro corporal". Traçando uma ruptura com o dualismo antropocêntrico, este campo tem sido o responsável por restituir ao corpo um lugar de privilégio, emancipando-o de sua longa letargia e posicionando-o como categoria autônoma de conhecimento. 


\section{Introducción}

Durante gran parte de la historia occidental el cuerpo fue considerado un obstáculo para la producción de conocimiento. Desde la Antigüedad clásica, pasando por el tardo medievalismo cristiano, el Renacimiento y la Modernidad, el cuerpo fue enunciado como un estadio degradado frente al espíritu, el alma o la mente. En tanto objeto, fue diseccionado por la anatomía, reproducido por el arte, descripto por antropometría, cuantificado por la estadística. En el campo de las epistemes humanas se lo silenció por considerarlo algo dado.

Se debió aguardar hasta las últimas décadas de siglo XX para que la corporalidad se erigiera como un campo de relevancia en las ciencias sociales. La fractura de las identidades colectivas de los años 70, la emergencia de nuevos nichos de mercado, la epistemología poscolonial y feminista, entre otros, asistieron a este reposicionamiento. Desde las ciencias sociales emergieron aportes que contribuyeron a superar la ignorancia del cuerpo y autonomizarlo como vector de sentido, como objeto de estudio y como metodología. Englobadas bajo el "giro corporal" estas vertientes forjaron una visión del cuerpo como un constructo cultural, simbólico e histórico, simultáneamente constituido y constituyente. No obstante, el corto recorrido de este campo lo convierte en una espacialidad magnánima, aún desestimada por gran parte de la literatura académica.

En este sentido, las siguientes páginas brindan una primera aproximación al derrotero de los estudios del cuerpo. Se trata de un recorrido que parte del cuerpo como objeto de investigación, desde su omisión y degradación, hasta su autonomización. Para ello, se tematizan apreciaciones del campo de la filosofía, el arte, la medicina y, más tardíamente, de la historia, la sociología y la antropología. En paralelo, se señala de qué forma ese abordaje se vio frecuentemente mitigado por la hipotética superioridad de la mente sobre la materialidad física, cómo la elocución del cuerpo estuvo perpetuamente sujeta a otras narrativas, y cómo finalmente el giro corporal se encargó de desarticular la desproblematización en la que se encontraba. Al final del recorrido el trabajo desliza cómo en los últimos años el cuerpo cesó de ser un mero objeto de investigación para convertirse en teoría y metodología. 
En una época en la que la informatización y digitalización parecen descorporizar la experiencia, resulta fundamental volver una vez más sobre el cuerpo y resituar su devenir histórico. Como menciona Foucault (1999), no hay territorialidades más intervenidas por el saber-poder que aquellas que no se problematizan. Es por ello que el objetivo apunta a realizar un barrido temporal y disciplinar que acerque la problemática a áreas de las ciencias donde el tema continúa inadvertido. Hurgando en el presente y en el pasado, el trabajo articula los testimonios más relevantes que han tratado de dar respuesta a la pregunta de qué es un cuerpo.

Aunque existen momentos en que ciertas representaciones se imponen sobre otras, no hay unilinealidad, causalidad o determinismo entre todos los factores, sino convivencia, fricción y yuxtaposición. Las corporalidades, en tanto objeto y dimensión ontológica, suponen una multiplicidad tan compleja que su sistematización escapa a cualquier esfuerzo académico. Es por ello que las siguientes páginas no se presentan como una totalidad cerrada, sino como un conjunto de disparadores abiertos a nuevas contribuciones.

\section{Silencio y subordinación}

No hay consenso en torno a qué es el cuerpo o cómo debería abordarse. Precisamente es esa multiplicidad de enfoques lo que le otorga una potencia inusitada. Existe, sin embargo, un sentido compartido dentro de esa multiplicidad: gran parte de las ciencias aún continúan silenciándolo por considerarlo una obviedad o lo desestiman por suponerlo un obstáculo al conocimiento.

La concepción del cuerpo como materialidad subordinada a la sustancia tiene un largo recorrido en la tradición occidental. Su germen puede hallarse en el dualismo ontológico esbozado en la Antigüedad clásica. La filosofía platónica desdoblaba la realidad en el plano de las ideas - un todo absoluto, inmutable, verdadero-y el plano sensible - copia ininteligible y degradada del original-. El sujeto se concebía como una entidad escindida, modulada por un alma (psique) y un cuerpo (soma) o, mejor dicho, un alma en un cuerpo, aprisionada en él (Platón, 1992). Aristóteles continuó en esta línea aseverando que el hombre era una sustancia compuesta de materia y forma; aunque a diferencia de Platón, consideraba que el alma no podía existir con inde- 
pendencia del cuerpo, no era trascendente o inmortal. Cuerpo y alma se fundían en un todo. A pesar de los matices, en ambas concepciones el alma se alzaba en detrimento de la materia.

Este homo dúplex griego fue reciclado por el cristianismo años más tarde. La vulnerabilidad de la carne, su condición pecadora y finita se institucionalizó como pilar de la escolástica de Santo Tomás de Aquino. El binario tomó un sesgo valorativo, donde lo sagrado se alzó por encima de la esfera terrenal y profana. La carne devino un asiento de la pasión y los instintos, permanentemente hostigado por el demonio y sus tentaciones (Corbin, 2005). Como sede del pecado, el cuerpo se esgrimió como algo que debía ser dominado. La abstinencia, la dieta y el ayuno cristalizaron como tecnologías de mortificación para purificarlo y expurgarlo. Pese a las múltiples ramificaciones de la metafísica cristiana, la tutela del cuerpo y la jerarquización del alma fueron una constante de la matriz de pensamiento. En su variante más radical, el ascetismo, el cuerpo se convirtió en un enemigo absoluto, un obstáculo hacia la divinidad.

El tratamiento denostado que recibió el cuerpo durante la Edad Media cambió de estatuto en el Renacimiento. El humanismo se convirtió en una grilla de sentido que medió todas las esferas intelectuales. Tanto el arte como la ciencia compartieron la misma inquietud por la morfología externa del cuerpo. La figura humana protagonizó la mayoría de las producciones. Se heredaron las representaciones pictóricas del mundo griego, que fijaban su atención en los cuerpos estilizados, blancos, atléticos y saludables. El realismo objetivo, la proporción y la perspectiva se tornaron en convenciones pictóricas, sinónimos inmediatos de belleza y armonía (Porter, 2009; Vigarello, 2005). El Vitruvio de Da Vinci canonizó la simetría universal del cuerpo humano y, por efecto, del especio entero. El cuerpo del varón, adulto, occidental, heterosexual se tornó la medida de todas las cosas.

El redescubrimiento continuaba, sin embargo, reproduciendo la jerarquía dualista. Se perpetuaban los vectores culturales configurados por la teoría humoralista del Corpus hipocrático (Porter, 2009). Estos tratados aseveraban que el ser humano era un conjunto de sustancias humorales encerradas en un envoltorio cutáneo. Las enfermedades no eran vistas como entidades nosológicas: la buena salud 
dependía de la dieta y del equilibrio esas sustancias (Paster, 1993). El cuerpo era considerado un simple contenedor de los cuatro humores: sangre, flema, bilis amarilla y bilis negra. Una irritación, inflamación o sangrado revestían un carácter moral, ya que la realidad se regía bajo el criterio de la semejanza: lo que se manifestaba en el mundo tangible - cuerpo - tenía su correlato en el mundo intangible-humores- (Foucault, 1996).

La medicina moderna se abrió paso en esta misma época bajo el pulso de la anatomía. La nueva técnica fraccionaba el cuerpo en partes más pequeñas para poder vincular el síntoma con la lesión orgánica. La práctica de la disección, desaparecida desde el período helenístico, reapareció para acompañar el proceso de fragmentación corporal (Faure, 2005). La pericia por debajo de la piel redimensionó los vínculos entre el yo interno y el mundo exterior. Al cuerpo se lo penetró, exhibió, desmembró. Se clasificaron sus partes. Se indagó en sus cavidades, huesos, vísceras y órganos. Bajo la inquisidora mirada médica, el cuerpo devino en un objeto susceptible de ser hurgado, alejándose definitivamente de la idea de dios (Porter, 2009). Los órganos dejaron de revestir significantes espirituales; el corazón, por ejemplo, se convirtió en el órgano encargado de bombear sangre.

Durante la primera modernidad las metáforas cristianas y humoralistas se erosionaron, y la causalidad mecanicista describió al cuerpo como un artilugio maquínico. La figura del reloj, con sus piezas y engranajes monopolizó su representación. La obra De Corporis humani fabrica de Andreas Vesalio sistematizó los postulados de la anatomía maridando el campo del arte, la medicina y la filosofía. El cuerpo fue señalado como una fábrica compuesta por tres tipos de sistemas: los sistemas constructivos, los sistemas unitivos o conectivos y los sistemas animadores o impulsivos. Asimismo, la invención del microscopio permitió observar a una escala desconocida, generando que las fibras, los filamentos y los tejidos embistieran el rol que anteriormente encarnaban los humores (Lip Licham, 2001).

Por la misma época la filosofía de René Descartes delineó una ontología del cuerpo y del ser, volviéndose axiomas hasta la actualidad. La escisión entre materia y abstracción teorizada por el modelo del cogito ergo sum definió una de las bases fundamentales del racionalismo occidental. Como trasciende de Meditaciones metafísicas (2009) el dua- 
lismo cuerpo-mente se expresaba en relación de jerarquía. El primero era definido como

todo aquello que está determinado por alguna figura, circunscrito en un lugar, que llena un espacio de modo que excluye de allí todo otro cuerpo, que es percibido por el tacto, la vista, el oído, el gusto, o el olor. (Descartes, 2009, p. 17)

El cuerpo se encontraba sometido a los avatares de la experimentación sensorial, por lo tanto, no gozaba de una existencia verificable. La mente, en cambio, era indivisible, no tenía materialidad, altura o profundidad. Era lo único trascendente y no podía ser arrebatado. Para el filósofo los cuerpos no sienten, ni piensan, no son algo en sí mismos, son un envoltorio, una res extensa que contiene res cogito. El ser humano es únicamente "una cosa que piensa, esto es, una mente, un alma, un intelecto, o una razón" (Descartes, 2009, p. 17). El peso ontológico recayó sobre la fórmula: la mente se es, el cuerpo se tiene.

El espacio recibió un tratamiento similar. Mientras el tiempo se teorizó como sustancia dinámica, el espacio cristalizó como un escenario estático, tridimensional, finito, sometido a leyes físicas invariables, relativas la física newtoniana. Análogo al criterio de res extensa el espacio se convirtió en un envase opaco donde las cosas se reúnen bajo el principio de contigüidad y simultaneidad; un escenario que se puede ver, tocar, medir, recorrer, y sobre el cual se inserta la dimensión social.

La noción cartesiana fue acompañada por el empirismo baconiano a través de la observación, la demostración y la práctica como pilares del conocimiento (Faure, 2005). El cuerpo se convirtió en un hecho cuantitativo sometido a las leyes generales de la física clásica. Tenía peso, densidad, forma y estatura. El materialismo lo tornó un objeto palpable - científicamente verificable- y cognoscible a través de la observación. No obstante, el conocimiento científico carecía de sujeto encarnado. El ocularcentrismo equiparó la visión a la perspectiva cartográfica, con un sujeto sin cuerpo - cogitans - ubicando cenitalmente al objeto por encima del espacio y del tiempo (Warf, 2009). El estatuto de verdad otorgado a la visión y asociado a la razón aletargó la experimentación a través de otros sentidos e invisibilizó al cuerpo como agente cognoscente. 
El siglo XVIII fue decisivo para el desarrollo capitalista y por eso mismo un momento de empobrecimiento de las corporalidades occidentales (Pérez Royo, 2019). La utopía productivista profundizó la visión del cuerpo como una máquina infatigable de trabajo, compuesta de engranajes, módulos y herramientas (Roldán, 2010). Los datos aportados por los estudios antropométricos contribuyeron a su disciplinamiento en pos de la productividad y la rentabilidad. Asimismo, la materia tributada por la raciología asistió a la producción de un aparato colonizador de cuerpos-otros (indígenas, negros, mujeres). Como paroxismo, la trata negrera occidental se erigió como la más importante maquinaria de colonización instrumental y sistemática de corporalidades ${ }^{1}$.

Hacia el siglo XIX, diferentes tecnologías emergieron para docilizar cuerpos colectivos e individuales. Entre ellas, la gimnasia se tornó un importante dispositivo de disciplinamiento canalizado por instituciones nacionalistas como la escuela y el ejército. El cuerpo se sometió al cálculo de los movimientos, los espacios y los tiempos (Vigarello y Holt, 2005). El ejercicio físico de la gimnasia, su regularidad y precisión se probó como una forma de gestión que otorgaba mayor fuerza y resistencia al cuerpo para realizar trabajos productivos.

En paralelo, emergió la figura del dandi, atenta al mantenimiento de la apariencia. La preocupación por destacarse de las capas sociales bajas lo llevó a pulir una silueta esbelta que, por primera vez, destacaba el pecho sobre el vientre (Vigarello y Holt, 2005). La dietética, el ideal de decencia y la rigurosidad del porte se estructuraron frente al grotesco cotidiano de los cuerpos, hasta entonces relegados a la esfera privada (Bajtín, 1994). La ociosidad aristocrática fue lentamente abandonada a favor de la actividad física. En el ámbito artístico el desnudo encontró un gran cubo de cultivo. El neoclasicismo y el romanticismo exaltaron el cuerpo de la mujer que en aquel entonces se encontraba, paradójicamente, muy hostigado por la moral imperante. La mirada voyerista del varón heterosexual canonizó el desnudo femenino como emblema de belleza. El cuerpo de la mujer fue exhibido una y otra

$1 \quad$ Si bien la esclavitud existió siempre, tanto por su magnitud como por su matriz cuantitativa, esta red de tráfico de cuerpos se destaca por encima de otras. 
vez como pasivo, dócil, virgen, lánguido y con un mínimo de energías (Berger, 2016).

A fines de siglo, el cuerpo se liberó de los rígidos movimientos de la gimnasia y el deporte adquirió hegemonía. Emergió el principio energético del funcionamiento corporal. Se mostraron las bondades de las operaciones fisiológicas frente a las fijaciones anatómicas (Vigarello y Holt, 2005). El cuerpo dejó de entenderse como una morfología cerrada, de mecánica funcional, para percibirse como un conjunto de energías y reacciones termodinámicas, biológicas y químicas (Vigarello y Holt, 2005). En este sentido, el trabajo cardiovascular, la respiración y la oxigenación de los músculos se mostró más eficaz para mejorar el rendimiento que la geometría gimnástica y el trabajo de fuerza.

Las técnicas de la fisiología aplicadas al uso del microscopio institucionalizaron una nueva escala de observación del hecho orgánico. La biología permitió entender el cuerpo como un conglomerado orgánico-químico, un mundo de microorganismos que coexisten con-en él. Con la atención puesta en las bacterias, los fluidos, las células, las reacciones químicas, la temperatura, el paradigma clínico y las lesiones anatómicas perdieron relevancia para semantizar las enfermedades (Faure, 2005). La vida comenzó a pensarse en términos de relación y de conflicto.

Sin embargo, a pesar del pasaje de una economía del cuerpo mecánica a una funcional y orgánica, la superioridad de lo no-corpóreo no fue mitigada. En cierto sentido, la concepción de alma - ahora "energías vitales" - como regente de lo orgánico continuó templando el imaginario. En esta dirección operaban también los valores burgueses que motivaban el cultivo del intelecto. La mente se asoció a la razón y la civilización, y el cuerpo orbitó entre el instinto y la barbarie. Incluso al interior del idealismo romántico antirracionalista primó la consciencia frente al materialismo (Porter, 2009).

Las múltiples grillas de sentido que atravesaron el abordaje de lo corporal (modulaciones religiosas, racionalistas, empiristas, fisiológicas, biológicas, raciales o educativas) no escaparon de la sublimación dualista. Múltiples autores coinciden en que este ha sido el principal motivo por el cual el cuerpo se mantuvo desproblematizado y rezagado como categoría autónoma de conocimiento. Desde la Antigüedad, 
el desarrollo de la epistemología se ha esbozado como un devenir lineal desprovisto de carnalidad, una marcha casi mecánica del intelecto (Pacheco Ladrón, 2004).

\section{Ruptura y emerger}

Los primeros gestos de ruptura con el consenso ético y ontológico que existía en torno al cuerpo pueden rastrearse en el siglo XIX desde la filosofía. Fundada sobre algunos preceptos spinozianos, Friedrich Nietzsche $(1998 ; 2003 ; 2008)$ se encargó de restituir la dimensión corporal y sensual como coordenadas de sentido. A través de una crítica sistemática al cristianismo, el filósofo alemán emancipó al cuerpo de aquel sentido de pobreza y degradación que se le había impreso durante siglos.

La torsión conceptual se dio, por un lado, con la idea de que el conocimiento consciente se formula a partir del lenguaje, anticipando una tentativa performativa del discurso. Por el otro, con la noción de que existe un lenguaje no verbal que emana de impulsos e instintos. El hombre, indicaba Nietzsche, aprehende la realidad no solo con la consciencia racional, sino con el goce estético: el tacto, el olor, el dolor. Frente a la dualidad mente-cuerpo, el filósofo propone una zona híbrida donde cuerpo y verbalidad se licúan. No hay posibilidad de abstracción sin materia. El pensamiento no existe sin el cuerpo porque es precisamente en el gesto, en la expresión, en el impulso, en el ademán, en el movimiento, donde se encarna el lenguaje, y es a través de esa carnalidad que se construye una mirada hacia la realidad (Nietzsche, 2008). El cuerpo es precisamente aquella instancia donde el pensamiento debe hundirse para superar el orden de lo indecible y para poder ser transmitido. El cuerpo ya no es para Nietzsche un envoltorio contenedor de un yo trascendental, sino un emerger de sí-mismo que constituye la subjetividad (Nietzsche, 1998) que, a su vez, no es singular sino una multiplicidad de fuerzas caóticas, fragmentarias y antagónicas. Nietzsche es quien tempranamente señala al cuerpo como una territorialidad histórica y, por lo tanto, susceptible de ser deconstruida.

Similares inquietudes germinaron en el campo del arte escénico. A fines de siglo XIX la danza contemporánea surgió como un rechazo al ballet clásico y sus rígidos movimientos. El nuevo estilo proponía 
una descontractura de la técnica y la liberalización de la expresión corporal. Por primera vez la cinestesia de la danza le dio autonomía al cuerpo y lo posicionó como el único portador de las estrategias estéticas (Kunst, 2019). En el movimiento no hay separación de sujeto y objeto, mente y la materia, no hay subordinación, ni sucesión, ni esquema racional-discursivo. El brazo no se eleva porque la mente le envía una orden. Lo que prevalece es la sinergia y la cognición visceral, la dilatación del cuerpo y la somatización de la experiencia. El cuerpo-que-danza no es un medio, sino un fin en sí mismo. Es autónomo incluso de las formulaciones culturales más enraizadas: no es varón ni mujer, se representa como una metáfora (Mallarmé en Kunst, 2019).

Bajo la hermenéutica de la sospecha, los aportes de Marx y Freud contribuyeron a visibilizar la dimensión corporal como hecho ontológico. El primero con la praxia materialista que remarca los cuerpos explotados de los trabajadores. Según nos recuerda, lo único que posee el proletario es su cuerpo y su fuerza de trabajo. El segundo, con el concepto de trieb o pulsión como un impulso dinámico que opera en la frontera del nivel orgánico y del psíquico. Para el psicoanálisis el cuerpo se convierte en una superficie topológica donde el síntoma y lo libidinal imprimen su huella como patologías, invirtiendo la fórmula de la medicina moderna (Faure, 2005). Este campo indagó en la liminalidad cuerpo-mente con la figura de la conversión, y con el concepto de inconsciente como una geografía invisible que estructura la subjetividad (Freud, 1991a). Al espacio trascendental, singular y universal kantiano Freud le objeta que el espacio no es una realidad anterior ni al cuerpo, ni a la psiquis que lo proyecta (Freud, 1991b). El carácter extenso del aparato psíquico disuelve la idea del cuerpo como unidad acabada, con límite en la piel. En Freud existe una semantización del cuerpo como lenguaje y el lenguaje como corporalidad, revelando que el cuerpo habla, aunque pocas veces es escuchado.

Hacia mediados de siglo XX Maurice Merleau-Ponty (1993) recogió estos fragmentos críticos y los sistematizó en su Fenomenología de la percepción. Esta obra configura una modalidad epistémica transversal al dualismo cartesiano. La ruptura está dada por el carácter relacional de la fenomenología que no explica los fenómenos en tanto objetos 
externos al sujeto, sino como mutuamente constituyentes. No hay modelos conceptuales, tan solo facticidad, empiria, inmediatez. Este testimonio hibrida el límite entre pensamiento y cuerpo, e impulsa la noción de que el contexto constituye el fenómeno (Pérez Riobello, 2008). El cuerpo aparece como espacialidad mediadora que da existencia a la consciencia y a las cosas, un plexo que simultáneamente es sujeto y objeto, una suerte de conciencia encarnada (Merleau-Ponty, 1993). Es en su propio movimiento que el cuerpo dispone la espacialidad y, al mismo tiempo, es dispuesta por ella.

Si el espacio cartesiano es fijo, absoluto, independiente del tiempo, escenario sobre el que las cosas se apoyan; entonces el espacio fenoménico es aquel que tiene curvatura propia, es relativo, constituyente y constituido. Los embates de la fenomenología al cogito cartesiano se forjaron en la proclama de que la existencia es primero corporal; en la afirmación de que existimos porque ocupamos un lugar corporal en el mundo (Merleau-Ponty, 1993). Sobre esta base Pierre Bourdieu edificará algunos años más tarde la noción del cuerpo como un locus de sentido; una espacialidad donde los patrones se subliman y al mismo tiempo se transforman (Citro, 2004). La idea de habitus será la puerta de entrada para una sociología reflexiva que generará conocimiento con y desde el cuerpo.

Por el lado de la sociología y la antropología fue Marcel Mauss (1936) con su estudio de las técnicas corporales el primero en sugerir que el cuerpo era una construcción socialmente determinada por las contingencias culturales (Roldán y Godoy, 2017). Mauss despertó un interés histórico y etnográfico en fenómenos que hasta entonces no existían como tales. Allí donde había "hechos varios", Mauss los conceptualizó y sistematizó. Su esfuerzo por trascender las teorías anatómicas y fisiológicas del cuerpo derivaron en la creación de un campo desconocido. El "padre de la etnología”, como se le considera, comenzó a indagar en las experimentaciones corporales de distintos grupos culturales, en sus movimientos, ademanes y posturas. Sus observaciones le permitieron definir las técnicas corporales como acoplamientos que están determinados no solo por la biología, sino por el espacio, la psicología y la cultura. Los actos que tienen finalidades físicas o mecánicas - caminar, nadar, comer - fueron definidos como habitus adquiridos (Mauss, 1936). Señalando la constitución cultural de lo corporal, 
Marcel Mauss desarticuló la consideración de que el cuerpo era dato universal, ubicuo y desespacializado.

Para consolidar lo corporal como un campo de indagación, los aportes de Foucault fueron fundamentales. Para el filósofo, el cuerpo humano existe en y a través de un sistema político, como resultado de las modulaciones de poder (Foucault, 1999). Por lo tanto, no hay una política que no sea política de los cuerpos. El agenciamiento cuerpo-poder es teorizado en dos grandes dimensiones: el anatomo poder, sublimado sobre los cuerpos individuales de las personas, y el biopoder, que actúa sobre los cuerpos colectivos. En conjunto forman la biopolítica, matriz de tecnologías de saber-poder que dociliza y normaliza los cuerpos a través de instituciones disciplinarias, prácticas discursivas o dispositivos securitarios. En Historia de la sexualidad (Foucault, 2018) el autor realiza una genealogía de la domesticación y prohibición del cuerpo deseante, y la aparición de la carne como nueva experiencia con el cristianismo. El materialismo del cuerpo lleva a Foucault a desafiar la fórmula platónica: el alma es la cárcel del cuerpo. Asimismo, en El cuerpo utópico (Foucault, 2010) describe un cuerpo que no solo es una materialidad que adolece, sino que actúa, recuerda y desea. El cuerpo no está en el espacio, es el punto cero del espacio, sin él no hay arriba, abajo, derecha, izquierda, frente, espalda, cerca, lejos. Todo espacio - real y utópico— existe a partir de él. El cuerpo es todo lo que hay.

\section{Giro y auge}

A partir de 1970 los aportes a una epistemología del cuerpo dejaron de ser esporádicos y se delineó un campo de estudios específico, mayoritariamente enmarcado en indagaciones antropológicas y sociológicas. Los factores contextuales tuvieron gran influencia en esta consolidación. La ruptura del consenso keynesiano trajo aparejada una serie de transformaciones a nivel cultural que desmontaron el entramado identitario vigente. La caída de los grandes paradigmas, los movimientos de descolonización, el descrédito en los proyectos político-ideológicos alternativos crearon las condiciones de posibilidad para la aparición de actores sociales hasta entonces invisibilizados tras la matriz de clase. Nuevos sujetos y nuevos cuerpos emergieron de los intersticios del metarrelato moderno, entre ellos, las minorías étnicas, los jóvenes, los homosexuales y las mujeres. 
Como contracara de la deslocalización, los flujos informacionales se afianzaron a escala global. La circulación fluida creó contactos con modalidades corporales alternativas. Los movimientos independentistas, el africanismo y el turismo cultural, propiciaron un acercamiento a cuerpos diferentes. En tanto que la penetración de corrientes orientales new age habilitaron una experimentación novedosa de la corporalidad occidental. La meditación desafió sus límites y su materialidad: ¿dónde empezaba y dónde terminaba el cuerpo? Los nuevos intercambios alentaron la adopción de prácticas culturales exóticas. Los tatuajes, las perforaciones y laceraciones a la piel fueron tecnologías de transgresión que diluyeron el carácter intocable del cuerpo (Le Breton, 2019). Los movimientos contraculturales como el beat y el hipismo colaboraron en la construcción de cuerpos no hegemónicos, alejados del ideal de virilidad masculina que encarnaron las clases proletarias durante el estado benefactor (Porter, 2009).

El cuerpo se situó en la órbita de la liberación, pero también en la del individualismo, la moda y el consumo. El narcisismo nutrió el cuerpo como objeto de culto: se lo debía respetar, luchar contra su obsolescencia y monitorear su funcionamiento (Lipovetsky, 1995). La obsesión por la salud, por la higiene, la estética y la cosmética abrió enormes nichos de mercado. La publicidad entronó un estereotipo corporal ligero, blanco, seductor, carente de realidad, que derivó en una vigilancia permanente sobre el envejecimiento, el peso, la piel, el pelo y sobre su postura, su alimentación y su vestimenta (Le Breton, 1995). El cuerpo se tornó un espectáculo exhibicionista.

A la exigencia de rendimiento se sumó el imperativo de felicidad que, dependiendo de cada cuerpo - gordo, flaco, joven, viejo, varón, mujer- recaía de distinta manera, tornándose más o menos complejo de satisfacer. La megalomanía occidental se desbalanceo con la explosión epidémica del sida en la década de 1980, que dejó al descubierto la vulnerabilidad del cuerpo, hecho largamente omitido por la modernidad (Porter, 2009).

La efervescencia de lo corporal intimó a reactualizar las coordenadas epistémicas de las ciencias sociales. La dificultad del paradigma nomológico-deductivo para teorizar una realidad fragmentaria devino en estudios que redimensionaron el rol del sujeto frente a la estructura. Los estudios posestructuralistas, culturalistas y poscoloniales abrieron 
una territorialidad cualitativa y localizada. La corporalidad, tanto fuera de la academia como al interior de ella, se tornó un hecho paradigmático, mientras en la literatura especializada comenzó a hablarse de un "giro corporal" (Sheets-Johnstone, 2009).

En el campo de la historiografía se destacaron las producciones de Jacques Le Goff acerca de las metáforas corporales de la edad media y los trabajos de Peter Brown del devenir corporal con la irrupción del cristianismo en la cultura clásica. Las producciones George Vigarello en torno a la belleza, la gordura, el deporte, la higiene y la pedagogía del cuerpo fueron testimonios ineludibles de cómo cada época inscribía sus huellas en las corporalidades. Junto con Alain Corbin y Jacques Courtine compilaron la faraónica Historia del cuerpo, una obra de tres volúmenes dedicada a historizar el cuerpo desde el Renacimiento hasta el siglo XX.

Por su parte, desde la antropología aparecieron tempranamente trabajos como los de John Blacking, Mary Douglas y Victor Turner retomando los planteos seminales de Mauss. En la sociología, Bryant Turner definió los estudios del cuerpo como el 'medio' del yo social, apartándose de las metáforas organicistas que abundaban en la sociología funcionalista hasta aquel entonces (Godoy, 2019). David Le Breton, por su parte, desarrolló una sociología del cuerpo y también de la piel, de la voz, el rostro y del dolor, entre otros. No obstante, poco de esto podría haber florecido sin la obra de Norbert Elias. Como un precursor de la sociología de las emociones y el cuerpo, este autor señalaba cómo las estructuras sociales y estatales tenían un impacto directo sobre la configuración de la subjetividad al crear afectaciones como la vergüenza, la repugnancia y el pudor. Sus textos exhiben tempranamente cómo la civilización supone un proceso de fagocitación de cuerpos individuales por parte de lo colectivo (Elias, 2011). Asimismo, Henri Lefebvre (2013) inauguró un nuevo entendimiento del espacio y del cuerpo con sus aportes a la geografía crítica. Con la categoría de espacio vivido el filósofo posicionó al cuerpo como la coordenada primera del espacio, aquel que lo significa, que tiene capacidad de acción y producción.

En este devenir, la teoría feminista merece especial atención. Si el cuerpo es un pliegue cultural, probablemente el cuerpo de la mujer sea el topos más colonizado y el que más laceraciones ha recibido. El 
patriarcado, en tanto institución de regulación de cuerpos a escala poblacional, ha considerado como único cuerpo válido el del varón, adulto, blanco, heterosexual. El de la mujer - confinada hasta el siglo XVII a un estadio presocial- nunca existió por derecho propio (Turner, 1989). Entre 1960 y 1970 los estudios anglosajones del feminismo de la segunda ola reconfiguraron los vínculos de la mujer con su propio cuerpo, por fuera de la mirada del varón. El cuerpo se volvió sujeto no objeto-de deseo y comenzó a emanciparse de su propia enajenación, de sus roles fantasmáticos de propiedad y ornamento. El feminismo radical con su lema "lo personal es político", develó que la opresión llegaba incluso a los lugares más íntimos y personales: el cuerpo.

La cristalización del giro corporal arribó con el posestructuralismo en los $90 \mathrm{y}$ el feminismo de la tercer fue uno de sus motores. Desmontando el binario de determinación sexo-genérica, estas teóricas crearon marcos conceptuales para contener las diversidades. Las corporalidades se colocaron en un lugar de privilegio y ello supuso renegociar sus representaciones, dejando al descubierto que no existía un cuerpo singular, sino una multiplicidad de cuerpos. El giro corporal abordado desde este lugar permitió visibilizar los cuerpos-otros que históricamente habían sido agredidos, patologizados y que habían permanecido ocultos detrás del cuerpo que se enunció como modelo normativo.

Autoras como Monique Wittig, Judith Butler, Gloria Anzaldúa, entre otras, denunciaron el orden binario del cuerpo sexuado y la obligatoriedad heterosexual. El cuerpo lesbiano de Wittig (1977) no es ni varón ni mujer, es un nuevo territorio con geografías erógenas descentradas, un cuerpo que fractura el ensamblaje mecánico pene-vagina. Wittig propuso una reapropiación de los discursos anatómicos y pornográficos que han funcionado como tecnologías de producción de cuerpos heterosexuales, para abrir la indagación hacia otras experticias corporales. En esta línea, el posporno se erigió como una propuesta crítica para decodificar el cuerpo normalizado. A través de prácticas que desgenitalizan el placer y quiebran la geografía moral del cuerpo, sostiene que todo el cuerpo puede ser erógeno.

Judith Butler (2002; 2007), en tanto, sentenciaba que el género no era una realidad ontológica sino una construcción performativa. El lenguaje y la repetición ritualizada de determinadas técnicas, gestos y movimientos, contornea la materialidad de los cuerpos, construye los 
horizontes simbólicos que luego determinan qué cuerpos son aceptados y cuales son rechazados. Para Butler, el simulacro del cuerpo femenino y masculino es puesto en evidencia por la figura de la Drag que, a través de un espectáculo lúdico y subversivo, performa la femineidad mucho mejor de lo que podría hacerlo cualquier mujer cisgénero, la tensiona y la desborda, la excede y la pervierte.

La figura del cyborg teorizada por la bióloga feminista Donna Haraway (1991) transforma el cuerpo masculinista y colonialista del cyborg original en una criatura posgenérica. A través de paisajes superpuestos la autora orquesta nuevos agenciamientos que no responden a la suma de dos partes. No existe máquina y hombre como cosas separadas, sino una internalización de la tecnología en el organismo. El cuerpo cyborg es una alternativa a las jerarquías ontológicas del humanismo antropocéntrico, una quimera de órganos, prótesis mecánicas, tejidos viscosos, ensambles maquínicos e injertos no humanos. $\mathrm{Al}$ respecto, la filósofa Rosi Braidotti (2015) teoriza este nuevo agente como lo poshumano. Evitando caer en las visiones que polarizan entre tecnofobia o tecnofilia, las autoras reconocen una continuidad entre el cuerpo y la tecnología, no una separación. No hay alteridad entre el ego y los otros, hay un modelo alternativo posantropocéntrico y medioambientalista.

Cuerpos, identidades y prácticas disidentes han sido el objeto de pensamiento de Paul B. Preciado (2016), para quien los cuerpos que le interesan son aquellos que tienen fallos en su estructura textual: los hermafroditas, intersexuales, locas, maricones, bollos, frígidas, asexuales. El filósofo propone una reivindicación del cuerpo perverso frente a la obligatoriedad binaria del cuerpo femenino-masculino, heterosexual-homosexual, cis-transgénero. Sometiéndose a una intoxicación voluntaria a base de testosterona, pone el cuerpo a su teoría, transformándolo en objeto y sujeto simultáneamente. A la versión butleriana del cuerpo y la identidad como efecto discursivo-performativo, Preciado le añade una versión más materialista. Además de técnicas semióticas, para que existan cuerpos femeninos o masculinos hay sometimiento somático con intervenciones endocrinológicas, quirúrgicas, farmacológicas, cosméticas o microprostéticas que performan esa feminidad o masculinidad. Existen biocódigos como la testosterona, el viagra, los anticonceptivos, la depilación laser, la pornografía y las pu- 
blicidades que, de forma consciente o inconsciente, actúan en la normalización de la anatomía material y psíquica. Ante las acusaciones biologicistas a los cuerpos trans o inter, Preciado $(2008 ; 2009)$ señala que no hay estatuto de naturalidad en ningún cuerpo, tampoco en los cisgénero. En todos los cuerpos el poder incrusta sus prótesis políticas y tecnológicas.

Asimismo, la noción de teoría queer acuñada por Teresa de Lauretis (1989) brindó un marco de contención a las figuras que quedaban al margen de la normalidad relativa al sexo, al género, al deseo y también al cuerpo. El término queer funcionó para aglutinar a aquellas corporalidades que asumen la frontera como espacio de reivindicación. Por ello la utopía de los feminismos queer no es heroica ni militarista, sino una utopía del cuidado de los cuerpos frágiles, de los cuerpos-otros, las anatomías aumentadas, las diversidades funcionales, los cuerpos no capacitistas, los fluidos, los no hegemónicos, etc.

Las propuestas de los feminismos disidentes escapan del binario en todas sus formas, no solo en lo relativo a lo sexo-genérico, sino a todo tipo de dualidades: objeto-sujeto, naturaleza-cultura, cuerpo-alma, máquina-organismo, yo-otro. Los nuevos materialismos restituyen a la materia un rol fundamental y al cuerpo su capacidad de agencia. No hay subjetividad encarnada, sino un modelo posnuclear viral-parasitario que se apoya en la inmanencia de categorías y especies (Braidotti, 2005). Así, el cuerpo no resulta una maquinaria separada del espacio, de otros, ni de sí mismo, como habría enunciado la modernidad, sino un devenir simpoiético con otros organismos, con el ambiente y la tecnología (Haraway, 2020).

Hermanada con estas nociones, la teoría del actor en red desarrollada por Latour, Callon y Law profundiza una mirada alternativa del cuerpo. Sujetos, objetos, espacio, relaciones sociales y materiales pierden su diferenciación en los enlaces de red. Los actantes humanos y no humanos se ponen en igualdad de condiciones a través de interacciones y asociaciones. La dicotomía del cuerpo que somos o el cuerpo que tenemos es superada por el cuerpo que actuamos o hacemos. Esta dimensión privilegia la situacionalidad y la acción encarnada. Por un lado, supera el conocimiento objetivo desde afuera - los discursos sobre el cuerpo- y por el otro, el conocimiento subjetivo desde adentro, que es experimentado y sentido individualmente por cada uno (Mol y 
Law, 2012). Es un cuerpo que incorpora, pero también excorpora sus acciones; habla, se mueve, muestra y manifiesta. La atención se desplaza hacia el entorno y se presenta un cuerpo activo que "incorpora fragmentos y piezas del mundo que lo rodea" (Mol y Law, 2012, p. 167).

En la era del capitalismo digital se proyecta un horizonte de interrogantes en torno a la materialidad del cuerpo. Como menciona Paula Sibila (2013) la tecnociencia se ha vuelto la responsable de la producción de cuerpos y subjetividades a escala global. La biología, que antes estudiaba anatomías individuales con límite en la piel, empezó a estudiar sistemas informáticos que procesan e intercambian datos (Haraway, 2020). Con la invención del genoma humano el cuerpo se textualizó a través de un alfabeto propio $-\mathrm{G}, \mathrm{C}, \mathrm{A}, \mathrm{T}-$. La tecnociencia puso el foco en unidades de análisis más pequeñas: el gen y el bit. Máquina y organismo se homologaron en su gimnasia, ambos se componen de unidades que pueden ser extraídas, manipuladas y recombinadas. Así es que existen alimentos transgénicos, semillas genéticamente modificadas, órganos sintéticos, chips subcutáneos, fecundación in vitro, cruzas de vectores animales, informáticos y vegetales. En tanto texto, todo cuerpo puede ser dispersado, desmontado y vuelto a ensamblar, sin arquitectura "natural" que obstaculicen el intercambio.

En sus paroxismos estas vertientes bogan por la pulsión fáustica de inmortalidad. En las ramas de las biotecnologías, las ingenierías genéticas y las biologías moleculares no se prescinde del cuerpo, lo interviene. A través de tecnologías nanomoleculares y algorítmicas, se apuesta alcanzar una perfectibilidad cuasi eugenista. En su rama informática, en cambio, se aspira a alcanzar la trascendencia a través de la inyección de la consciencia en un sistema operativo. De este modo, el cuerpo se torna algo más cercano al upgrade que al hecho orgánico, perpetuando la superioridad de la mente sobre la carne. Esta postura defiende la virtualidad como fenómeno de desmaterialización y lo analógico como reducto último de materialidad y localización (Martínez Luna, 2019). Algunos intelectuales cuestionan estos postulados: ¿es posible o acaso deseable existir sin cuerpo?

Una amplia literatura reformula las relaciones entre cuerpo y virtualidad. Las pantallas se rebelan como dispositivos complejos que no responden a la oposición real-virtual (Sibila, 2013; Steyerl, 2020; Valderatto, 2011). La pregunta por la imagen no orbita en torno a cómo 
las pantallas muestran el cuerpo, sino al hecho de si existe cuerpo en la imagen e imagen en el cuerpo. La respuesta insinúa que las imágenes no son representaciones del mundo, sino fragmentos de él (Steyerl, 2020). Así, la interfaz no representa al cuerpo ni lo desmaterializa, en su lugar, lo produce, lo transforma y lo difracta. Las técnicas semióticas que parten de la imagen generan intervenciones somáticas, de manera que el cuerpo no emerge $a$ través de las pantallas sino a partir de ellas (Denkard, 2011). No estamos eximidos del cuerpo cuando virtualizamos las relaciones. Como lo demuestra la avatarización, el cuerpo se desdobla en su singularidad, se fragmenta y se multiplica. El usuario es simultáneamente la escultura virtual de la pantalla y el cuerpo fuera de ella.

Las experiencias de inmersión virtual sitúan el cuerpo en una base de datos interactivos visualizable, explorable y manipulable en tiempo real. La digitalización llega a los órganos y los sentidos (Sibila, 2013). Con las tecnologías digitales, el dataísmo, los entornos sintéticos o la realidad aumentada, la ontología del sujeto y su cuerpo se desplaza hacia experiencias novedosas, encarnando un simulacro hiperreal. El cuerpo no desaparece en la sociedad posfordista, sino que se rematerializa. Utilizando la metafórica de Bauman, el cuerpo informatizado se desplaza con facilidad, fluye, gotea, desborda, salpica y cambia su forma. En palabras de Jean Luc Nancy, es un cuerpo siempre invadido por lo otro, que no es uno sino varios. Estos cuerpos "nada que ver con los dualismos, monismos o fenomenologías. El cuerpo no es ni substancia, ni fenómeno, ni carne, ni significación. Solo ser excrito" (Nancy, 2003, p. 19).

\section{Estudios desde el cuerpo}

Numerosas perspectivas han desplazado la corporalidad en tanto objeto para refundarlo como sujeto, metodología y epistemología. La antropología fue el área donde más se profundizó en este sentido. Las indagaciones comenzaron en las últimas décadas y hundieron sus raíces en la descolonización epistémica. Estuvieron guiadas por la crítica a los supuestos de la etnografía tradicional racionalista, que sostenía que era posible aprehender de forma neutral el objeto, reduciendo al mínimo las inferencias subjetivas (Citro, 2009). Esta epistemología se vio reforzada la década del 80 por una tendencia a la textualización de las 
culturas y de la práctica etnográfica (Howes, 2014). Frente a ello emergieron indagaciones que atendían no solo al cuerpo en el campo, sino al campo desde el cuerpo, fomentando una exploración que comprometía directamente la corporalidad en la producción de conocimiento.

En los intersticios del paradigma de la cultura del texto de Cliffort Geertz (2003), la noción del embodiment de Thomas Csordas (1999) fue una de las primeras categorías en dar cuenta de la urgente necesidad de crear un acercamiento corpóreo al objeto de estudio. La sociedad se encarna en el cuerpo, en sus gestos, en sus movimientos y, al mismo tiempo, el acercamiento al hecho social se da desde el cuerpo. Asimismo, el concepto de "mímesis" de Michael Taussig (1993) desplazó a la visión como única coordenada de conocimiento, para incorporar el olfato, el tacto, el oído y la intuición. Con la experimentación háptica del cuerpo, la visión, sentido que históricamente había estado ligado a la mesura y a la razón científica, comenzó a mostrarse como un ejercicio de traducción, un dispositivo cultural, carnal y artístico. En la misma línea, la "participación observante" de Rosana Guber (2011) invirtió la clásica fórmula etnográfica: la autora argumenta que no es posible observar sin participar. Para dar cuenta de esta tarea el investigador debe asumir el desafío de la distancia y la cercanía inherente a la observación y la participación. Debe ubicarse simultáneamente cerca y lejos, dentro y fuera del objeto, en un ejercicio de afectación reflexivo con las prácticas del entorno. Silvia Citro (2004) propone una metodología de doble arista que articula dos escalas de análisis diferentes: por un lado, una perspectiva cenital y teórica desde la fenomenología y la hermenéutica de la sospecha para contextualizar el devenir histórico del objeto de estudio; por el otro, una metodología etnográfica y corporal que logre relativizar las abstracciones y encontrar las resistencias a los modelos. Empiria y teoría, textura y escritura, contexto y texto, se funden en la llamada dialéctica de la corporalidad.

La idea moderna de ausencia de un sujeto cognoscente detrás del conocimiento fue problematizada por los postulados epistemológicos del "conocimiento situado" de Haraway (1991) y la "política de la ubicación" de Adrianne Rich (1987). Ambos dispositivos señalaron que el científico detrás del objeto de estudio no estaba desprovisto de un cuerpo y, como tal, su conocimiento era siempre parcial y fragmentario. Señalaban además que no existe un acto de visión que no im- 
plique, en un mismo gesto, interferencia y modificación, tensionando los postulados del régimen escópico. La ciencia no describe datos, sino que los produce desde el cuerpo.

Al respecto, la sociología carnal de Loic Wacquant trabaja y radicaliza la noción de habitus bourdesiana, en tanto deja de esgrimir al cuerpo únicamente como fuente de simbolismos, para considerarlo un locus de la práctica social. El habitus es un estado encarnado en el cuerpo que da cuenta del agente y la estructura. De tal manera, funciona como un dispositivo teórico-metodológico que permite la experimentación carnal, siendo en, con y un mundo (Wacquant, 2006; 2008/2009). Con la etnografía de inmersión, el sociólogo francés pone a disposición su cuerpo para que diseccione y, al mismo tiempo, sea diseccionado por las fuerzas materiales y simbólicas que componen el escenario empírico.

Asimismo, superando la histórica dualidad pensamiento-cuerpo, en la última década ganaron terreno los denominados estudios sensoriales que suponen "una aproximación cultural al estudio de los sentidos, al igual que una aproximación sensorial sobre el estudio de la cultura" (Howes, 2014 p. 11). Las etnografías sensoriales proponen una aproximación en la liminalidad de lo corpóreo y lo afectivo, la percepción y la sensación, la razón y la emoción. Como menciona Sabido Ramos (2019) "los cuerpos sienten y ese sentir dan sentido al mundo" (p. 17). Los sentidos median la relación entre la idea y el objeto, y por ello la ciencia se debe hacer partiendo de lo sensorial. Profundizando en esta línea, algunas propuestas han pasado de la participación observante a las performances participativas como metodología transdisciplinar de investigación (Citro, et al., 2019). Para diversificar la reflexividad y profundizar las formas de conocimiento invisibilizada por los formatos académicos tradicionales, se apela a metodologías performáticas - gestos, posturas, movimientos, sonoridades - provenientes de las artes teatrales.

Entregarse a la sumisión sensual como variable teórico-metodológica supone indagar en las estéticas visuales y textuales, pero también en los escenarios sonoros, olfativos, gestuales, en las configuraciones espaciales, en los flujos de movilidades, etc. A diferencia de otras vertientes, en la propuesta de poner el cuerpo a la investigación se revela una ontología prelingüística de la corporalidad. El cuerpo se convierte en una herramienta que hurga en la conducta ilegible, en 
los esquemas prediscursivos, internalizados y viscerales (Wacquant, 2008/2009). Poner el cuerpo supone asumir que existen fenómenos inscriptos en la frontera de lo decible, que no puede ser explicitado desde la teoría o el discurso, que no pueden ser enunciados ni transmitidos, sino únicamente incorporados en la práctica. Con ello, la metodología del cuerpo desafía la holgada posición académica y rompe con la inercia de ciertas prácticas científicas (Roldán y Mauro, 2008/2009), llevando al investigador a la performática de la praxis.

A partir del giro, la corporalidad se convirtió en una variable autónoma, capaz de producir y encarnar conocimientos con independencia de otras narrativas. Se transformó, en otras palabras, en aquel otrode-mí facilitador del entendimiento meta-visual y meta-discursivo, un quiebre epistemológico que matizó el monopolio de la visión, la razón y el texto como únicos productores de conocimiento.

\section{Conclusiones}

El derrotero transitado muestra cómo paulatinamente el cuerpo pasó de ser un hecho silenciado, poco más que un obstáculo, a ser considerado un vector privilegiado en la producción del saber. Como se trató de dar cuenta, el emerger de los estudios corporales estuvo ligado a la disputa por los sentidos ontológicos del ser humano. Desde la Antigüedad temprana, la concepción dualista del hombre occidental se enquistó en la mayoría de las narrativas - religiosas, metafísicas, artísticas, epistémicas, etc.-, cancelando la corporalidad como productora de sentido. En las áreas de la ciencia duras el cuerpo fue tematizado primero por el campo de la mecánica y la física, luego por el organicismo de la biología, la fisiología y la química. En la actualidad la tecnociencia en sus ramas informáticas y biotecnológicas son las encargadas de resemantizarlo como objeto de estudio. No obstante, a pesar de estar cifrado bajo diferentes lógicas, lo corporal continuó subordinado. Durante siglos se perpetuó la axiomática que encumbra al alma, el espíritu o la mente en detrimento de la materialidad del cuerpo.

Nutrido por el posestructuralismo, el giro corporal permitió que el cuerpo transitara por andamiajes teóricos diferentes. Se habilitaron epistemologías, estéticas, sensibilidades y prácticas novedosas. El cuerpo comenzó a ser pensado como un soporte material y simbólico, último y primario de toda la interacción social (Roldán y Godoy, 2017); 
como un indicador de la relación con el mundo (Le Breton, 2011); como un asiento de la subjetividad en el que se expresan los códigos de la cultura - condiciones de trabajo, clase social, alimentación, género, edad, moda, consumos, códigos mediáticos- (Marcús, 2012); como un ensamblaje inteligente de categorías simbólicas, capacidades y antojos, no solo socialmente construido, sino también socialmente productor (Wacquant, 2008/2009). Estas visiones dejaron en claro que el cuerpo no ocupa un espacio, sino que es un espacio.

Las operaciones recuperaron el cuerpo y también al sujeto como una unidad social, cultural, de género, circunstancial, histórica y espacialmente determinada (Pacheco Ladrón, 2004). Situar al sujeto corpóreo en una coordenada témporo-espacial implica asumir que el cuerpo no puede ser un dato abstracto o ahistórico, ya que los cuerpos son esencialmente localizaciones, unidades de tiempo, espacio y cultura, por lo tanto, no existe un cuerpo en singular, ni una sola forma de habitarlo.

Castro Gómez (1996) menciona que conocer es un acto de violencia, es someter, es dominar, reducir a unidad, objetivar. Sin embargo, desconocer también lo es. De la misma manera que el cuerpo, el espacio quedó durante mucho tiempo atrapado en el hiato de omisión, solapado por las dimensiones social y temporal de las ciencias humanas (Soja, 2010). Con el giro espacial de los últimos años, sin embargo, el espacio dejó de verse como un simple escenario hiperconcreto que reúne lo social, para enunciarse como un entramado dinámico de relaciones, la que a su vez son soportadas e inscriptas en el cuerpo (Roldan y Godoy, 2017). Reposicionar dimensiones de estudio que fueron ignoradas durante años, indagar y trazar puentes entre ellas es una inventiva para abrir nuevos horizontes epistémicos al interior de las ciencias sociales. Debemos encontrar articulaciones novedosas para pensar los desplazamientos de cuerpos, objetos, informaciones y tecnologías. Frente a las nociones euclidianas del espacio, frente a la dualidad cartesiana del cuerpo, frente a los esencialismos o la noción de sedentarismo, la movilidad ofrece nuevas claves de lectura a los problemas sociales, tal vez más pertinentes para indagar en el mundo informatizado y global contemporáneo.

Visibilizar el devenir del cuerpo, así como el de tantos otros tópicos silenciados por las ciencias sociales, es un acto de apertura hacia nue- 
vas gestas epistémicas. Politizar y reconstruir la historicidad de cada fenómeno es una apuesta hacia un paradigma que se nutra del agenciamiento subjetivo y de la visión crítica, y que sea capaz de disputar y descentrar aquellos sentidos más naturalizados en la producción del conocimiento.

\section{Referencias}

Bajtín, M. (1994). La cultura popular en la Edad Media y en el Renacimiento. Alianza.

Berger, J. (2016). Modos de ver. Gustavo Gili Editorial.

Braidotti, R. (2005). Metamorfosis. Hacia una teoría materialista del devenir. Akal.

Braidotti, R. (2015). Lo poshumano. Gedisa.

Butler, J. (2002). Cuerpos que importan: sobre los límites materiales y discursivos del "sexo". Paidós.

Butler, J. (2007). El género en disputa. El feminismo y la subversión de la identidad. Paidós.

Castro-Gómez, S. (1996). Narrativas contramodernas y teorías poscoloniales. En S. Castro-Gómez, Crítica de la razón latinoamericana (pp. 145-170). Puvill Libros.

Citro, S. (25-28 de mayo de 2004). Simposio: propuestas para una antropología del cuerpo. La construcción de una antropología del cuerpo: propuestas para un abordaje dialéctico. VII Congreso argentino de Antropología social. Universidad Nacional de Córdoba, Córdoba, Argentina.

Citro, S. (2009). Cuerpos significantes. Travesías de una etnografía dialéctica. Biblos.

Citro, S., Greco, L., y Agüero, S. (2019). Las corporalidades de la etnografía: de la participación observante a la performance-investigación colaborativa. En L. Catzer y H. Chivazza (Eds.), Perspectivas etnográficas contemporáneas en Argentina (pp. 103-172). Universidad Nacional de Cuyo, UNCUYO.

Corbin, A. (Comp.) (2005). Historia del cuerpo, Vol. 2. De la Revolución francesa a la Gran Guerra. Taurus.

Csordas, T. (1999). Embodiment and cultural phenomenology. En G. Weiss y H. Fern Haber (Eds), Perspectives on Embodiment (pp. 143-162). Routledge. 
De Lauretis, T. (1989). Technologies of gender. Essays on theory, film and fiction. Macmillan Press.

Descartes, R. (2009). Meditaciones metafísicas. https://blocs.xtec.cat/ filocostaillobera/files/2009/03/Descartes-Meditacionesmetaf\%C3\%ADsicas.pdf

Drenkard, P. (2011). Modos de ser y estar en tiempos posmodernos: sujeto, cuerpo, virtualidad. En S. Valdettaro (Coord.), Interfaces y pantallas. Análisis de dispositivos de comunicación (pp. 37 52). Universidad Nacional de Rosario, UNR editora.

Elias, N. (2011). El proceso de civilización. Investigaciones sociogenéticas y psicogenéticas. Fondo de Cultura Económica.

Faure, O. (2005). La mirada de los médicos. En A. Corbin (Comp.), Historia del cuerpo, Vol. 2. De la Revolución francesa a la Gran Guerra (pp. 23-56). Taurus.

Foucault, M. (1996). Las palabras y las cosas, una arqueología de las ciencias humanas. Siglo XXI Editores.

Foucault, M. (1999). Diálogo sobre el poder. Obras esenciales III. Paidós.

Foucault, M. (2010). El cuerpo utópico. Nueva visión.

Foucault, M. (2018). Historia de la sexualidad IV. Confesiones de la carne. Siglo XXI editores.

Freud, S. (1991a). La interpretación de los sueños. Obras completas. Volumen $V$. Amorrortu.

Freud, S. (1991b). Moisés y la religión monoteísta. Esquema del psicoanálisis y otras obras. Obras completas. Volumen XXIII. Amorrortu.

Geertz, C. (2003). La interpretación de las culturas. Gedisa.

Godoy, S. (2019). Las culturas sobre el río. Gubernamentalidad, prácticas y habitares. Ribera central de Rosario 1992-2004 [Tesis doctoral no publicada]. Universidad Nacional de Rosario, UNR.

Guber, R. (2011). La etnografía. Método, campo y reflexividad. Siglo XXI Editores.

Haraway, D. (1991). Ciencia, cyborgs y mujeres. La reinvención de la naturaleza. Feminismos.

Haraway, D. (2020). Seguir con el problema. Generar parentesco en el Chthuluceno. Consoni. 
Howes, D. (2014). El creciente campo de los estudios sensoriales. Revista Latinoamericana de Estudios sobre Cuerpos, Emociones y Sociedad, 6(15), 10-26. https://www.redalyc.org/ pdf/2732/273231878002.pdf

Kunst, B. (2019). Los cuerpos autónomos de la danza. En B. Hang y A. Muñoz (Eds.), El tiempo es lo único que tenemos. Actualidad de las artes performativas (pp. 51-66). Caja negra.

Le Breton, D. (1995). Antropología del cuerpo y modernidad. Nueva visión.

Le Breton, D. (2011). La sociología del cuerpo. Nueva visión.

Le Breton, D. (2019). La piel y la marca. Acerca de las autolesiones. Topia.

Lefebvre, H. (2013). La producción del espacio. Capitán Swing.

Lip Lichman, C. (2001). El paradigma indiciario en la medicina. Revista Médica Herediana, 12(2), 65-74. http://www.scielo.org.pe/ $\mathrm{pdf} / \mathrm{rmh} / \mathrm{v} 12 \mathrm{n} 2 / \mathrm{v} 12 \mathrm{n} 2 \mathrm{ce} 1 . \mathrm{pdf}$

Lipovetsky, G. (1995). La era del vacío. Ensayos sobre el individualismo contemporáneo. Anagrama.

Marcús, J. (2012). La configuración sociocultural de los cuerpos. Revista Tram [p]as de la comunicación y la cultura, (70). http:// sedici.unlp.edu.ar/handle/10915/35267

Martínez Luna, S. (2019). Cultura visual. La pregunta por la imagen. Sans Soleil.

Mauss, M. (1936). Técnicas y movimientos corporales. Journal de Psychologie, 32(3-4), 1-23. http://classiques.uqac.ca/classiques/mauss_marcel/socio_et_anthropo/6_Techniques_ corps/techniques_corps.pdf

Merleau-Ponty, M. (1993). Fenomenología de la percepción. PlanetaAgostini.

Mol, A. y Law, J. (2012). Acción encarnada, cuerpos actuados. El ejemplo de la hipoglucemia. En R. Ibáñez Martin y E. Pérez Sedeño (Eds.), Cuerpos y diferencias (pp. 153-177). Plaza y Valdés.

Nancy, J. L. (2003). Corpus. Arenas.

Nietzsche, F. (1998). Así habló Zaratustra. Alianza.

Nietzsche, F. (2003) Cómo se filosofa a martillazos. Longseller.

Nietzsche, F. (2008). El anticristo. Ediciones Libertador.

Pacheco Ladrón, L. (2004). El horizonte epistémico del cuerpo. Región y Sociedad, 16(30), 185-194. http://www.scielo.org.mx/pdf/ regsoc/v16n30/v16n30a6.pdf 
Paster, K. G. (1993). The body embarrassed: Drama and the disciplines of Shame in early England. Itaca.

Pérez Riobello, A. (2008). Merleau Ponty: percepción, corporalidad y mundo. Eikasia, Revista de Filosofía, 4(20), 197-220. https:// revistadefilosofia.org/20-06.pdf

Pérez Royo, V. (2019). Corporalidades disidentes en la celebración. Fiesta y política en la escena contemporánea. El tiempo es lo único que tenemos. Actualidad de las artes performativas. Caja negra.

Platón (1992). República, Libro VII. Gredos.

Porter, R. (2009). Historia del cuerpo revisada. En P. Burker (Comp.), Formas de hacer Historia (pp. 255-287). Alianza.

Preciado, P. B. (2008). Testo Yonqui. Espasa.

Preciado, P. B. (2009). Biopolítica del género. http://capacitacioncontinua.sociales.uba.ar/wp-content/uploads/sites/25/2016/10/ PRECIADO-Biopolitica-del-genero.pdf

Preciado, P. B. (2016). Manifiesto contrasexual. Anagrama.

Rich, A. (1987). Blood, bread and poetry. Virago Press.

Roldán, D. (2010). Discursos alrededor del cuerpo, la máquina, la energía y la fatiga: hibridaciones culturales en la Argentina fin-de-siècle. Revista Historia, Ciencia e Saude, Manguinhos, 17(3). https://doi.org/10.1590/S0104-59702010000300005

Roldán, D. y Godoy, S. (2017). Cuerpos, movilidades y espacios. La calle recreativa de Rosario (Argentina). Inmediaciones de la comunicación, 12(1), 129-153. https://doi.org/10.18861/ ic.2017.12.1.2669

Roldán, D. y Mauro, D. (2008/2009). Por una ciencia desde el cuerpo. Pensar. Epistemología, política y ciencias sociales, 3-4, 1-10. https://www.revistapensar.org/index.php/pensar/article/ view/27/22

Sabido Ramos, O. (Coord.) (2019). Los sentidos del cuerpo: un giro sensorial en la investigación social y los estudios de género. Centro e Investigaciones y Estudios de Género, CIEG, Universidad Nacional Autónoma e México, UNAM.

Sheets-Johnstone, M. (2009). The corporeal turn. Imprint Academic.

Sibila, P. (2013). El hombre postorgánico. Cuerpo, subjetividad y tecnologías digitales. Fondo de Cultura Económica. 
Soja, E. (2010). Tercer espacio. El alcance de la imaginación geográfica. En A. Albet y N. Benach (Eds.), La perspectiva posmoderna de un geógrafo radical (pp. 181-209). Icaria.

Steyerl, H. (2020). Los condenados de la pantalla. Caja Negra.

Taussig, M. (1993). Mimesis and alterity: A part history of the senses. Routledge.

Turner, B. (1989). El cuerpo y la sociedad. Exploraciones en teoría social. Fondo de Cultura Económica.

Valderatto, S. (Coord.) (2011). Interfaces y pantallas. Análisis de dispositivos de comunicación. Universidad Nacional de Rosario, UNR editora.

Vigarello, G. (Comp.) (2005). Historia del cuerpo, Vol. I. Del Renacimiento a la Ilustración. Taurus.

Vigarello, G. y Holt, R. (2005). El cuerpo cultivado: gimnastas y deportistas. En A. Corbin, (Comp.), Historia del cuerpo, Vol. 2. De la Revolución francesa a la Gran Guerra. Taurus.

Wacquant, L. (2006). Entre las cuerdas. Cuadernos de un aprendiz de boxeador. Siglo XXI Editores.

Wacquant, L. (2008/2009). Conexiones carnales. Sobre corporización, aprendizaje y pertenencia. Pensar. Epistemología, política y ciencias sociales, 3-4, 11-41. https://www.revistapensar.org/ index.php/pensar/article/view/28/23

Warf, B. (2009). De las superficies a las redes. En B. Warf. y S. Arias (Eds.), The spatial turn. Interdisciplinary perspectives (pp. 6076). Routledge.

Wittig, M. (1977). El cuerpo lesbiano. Pre-textos. 